\title{
Study of Mental IIIness in Rat Model of Sodium Azide Induced Oxidative Stress
}

\author{
Muhammad Farhan*, Hira Rafi, Hamna Rafiq, Fahad Siddiqui, Ruba Khan and Javeria Anis \\ Neurochemistry and Biochemical Neuropharmacology Research Unit, Department of Biochemistry, University \\ of Karachi, Karachi, Pakistan
}

\begin{abstract}
Aim: Oxidative stress is known as Reactive oxygen species (ROS) accumulation that is caused by reactive ROS and antioxidants imbalance that could be due to decreased antioxidant levels. Oxidative stress is often related to aging, Oxygen metabolism and redox imbalance in cells and tissues. It is a cellular state in which oxidants levels e.g. superoxide $\left(\mathrm{O}_{2}^{-}\right)$, hydrogen peroxide $\left(\mathrm{H}_{2} \mathrm{O}_{2}\right)$ or nitric oxide $(\mathrm{NO})$ in biological metabolisms exceed the oxidants scavenging capacity of cells. Oxidative stress in brain leads to depression, anxiety, memory impairment and behavioral deficits associated with them.
\end{abstract}

Method: 24 male albino wistar rats were allocated into test and controls groups administered with sodium azide $(5 \mathrm{mg} / \mathrm{kg}$ bodyweight) (i.p.) and water (p.o.) respectively for 14 days. Behaviors were monitored weekly after 24 hours of sodium azide administration in light/dark box, elevated plus maze, Open field and Morris water maze.

Results: Test animals that were administered with sodium azide significantly decreased entries and time spent in illuminated area of light dark box and elevated plus maze while increased latency and fewer square crossed were observed with decreased learning acquisition and memory retention.

Conclusion: All the data collected and results analysis determine oxidative stress could cause mood disorders learning disabilities. Sodium azide induced oxidative stress produce behavioral deficits and memory impairment validated it as a neurotoxin

Keywords: Oxidative Stress, Behavioral Deficits, Memory Impairment, Anxiety, Sodium Azide.

\section{INTRODUCTION}

Oxidative stress is the accumulation of Reactive oxygen species (ROS) species which is caused by imbalance in ROS and antioxidants due to reduced antioxidants level. Often oxidative stress is connected to aging [1], oxygen metabolism in biological systems [2], physiology of mitochondria [3], and redox imbalance study in cells [4]. Oxidative stress is a redox imbalance in redox couples found in cells or in various cellular sub-components [5]. Whereas, rapid or chronic enhancement in ROS steady state concentration induces oxidative stress distressing metabolism and regulation of cells and destructing cellular components [6]. Among all, brain is more susceptible to oxidative stress to due to increased redox active copper and iron levels. Antioxidants play a fundamental role in reducing ROS via enzymes that are catalase (CAT), superoxide dismutase (SOD), glutathione peroxidase (GP) and reductase $(G R)$ and in repairing of damaged tissues.

Gingrich in 2005 suggested that oxidative stress is the novel sort of stress which relates the rational association between psychological stresses with

*Address correspondence to this author at the Neurochemistry and Biochemical Neuropharmacology Research Unit, Department of Biochemistry, University of Karachi, Karachi-75270, Pakistan;

E-mail: farhankamali@uok.edu.pk

ISSN: 2223-3806 / E-ISSN: 1927-5951/19 increased levels of physiological oxidative destruction [7-10]. ROS species are generated as intermediates when oxygen is reduced to water [11] including superoxide $\left(\mathrm{O}_{2}{ }^{-}\right)$, hydrogen peroxide $\left(\mathrm{H}_{2} \mathrm{O}_{2}\right)$ and hydroxyl $\left(\mathrm{OH}^{-}\right)$radicals. Oxidative stress is produced due to overproduction of ROS species or inefficient antioxidant protective mechanisms against pro oxidants $[12,13]$. ROS species may have harmful effects [13] which affect the sustainability of DNA via mutations or modifications of genes expressions [14]. Oxidative stress is a cellular state where oxidants levels (hydrogen peroxide $\left(\mathrm{H}_{2} \mathrm{O}_{2}{ }^{-}\right)$, superoxide $\left(\mathrm{O}_{2}{ }^{-}\right)$or nitric oxide (NO) released in biological metabolisms exceeds the cell's capability of scavenging oxidants resulting in aberrant cellular molecules (DNA, proteins, lipids) and functions [15] which leads to apoptosis or lethality [1618].

Sodium azide is a crystalline and colorless powder [19]. NaN3 decomposes upon heating producing toxic fumes [20]. Studies using tissue homogenates and animal models revealed complete metabolism of azide predominantly in liver [21] producing toxic metabolite nitrogen oxide [22]. NaN3 is an acute neurotoxic substance $[23,24]$. Cellular toxicity of sodium azide has been validated by various experimental studies that have described its mechanisms as a neuronal toxin [25]. NaN3partially inhibits the respiratory chain in

() 2019 SET Publisher 
mitochondria that yields free radicals, moderates metabolism of energy aerobically and induces excitotoxic damages that lead to neurodegenerative diseases [26]. Systemic or local administration of NaN3 induces the production of excitotoxins due to destruction of mitochondrial energy machinery which results in neuronal cell damage [27]. Sodium azide induced metabolic and cellular destructions is also interconnected with synaptic denervation, cellular damages and behavioral deficits in various diseases $[28,29]$.

Present experimental study was designed to determine the neurotoxic properties of NaN3 induced behavioral deficits in rat model of oxidative stress in various behavioral paradigms.

\section{MATERIAL AND METHODS}

\section{Subjects}

All experimental animals were tested according to the institutional ethics and care committee guidelines. 24 Albino wistar adult male rats weighing between (120-180 gm) were obtained from Dow University of health and sciences, Karachi and had been randomly divided into two groups. All animals were housed in separately in cages and were given commercially available rat diet and water under standardized conditions (ambient $25 \pm 2{ }^{\circ} \mathrm{C}$ temperatures and light/dark cycle of $12 / 12 \mathrm{~h}$ ).

\section{Drugs}

Sodium azide (NaN3) was obtained from Sigma Aldrich chemicals, USA. NaN3 (5 mg/Kg BW) was administered intraperitoneally whereas; water as control was delivered orally using a stainless steel oral gavage daily. $\mathrm{NaN}_{3}$ were prepared in distilled water at $1: 1 \mathrm{w} / \mathrm{v}$ ratio.

\section{Experimental Procedure}

24 male rats were distributed randomly into two groups each that receive the following: water orally as a control group and a single dose of Sodium azide intraperitoneally (i.p.) $5 \mathrm{mg} / \mathrm{Kg} \mathrm{BW}$ (test group) daily for 14 days. All behaviors were recorded 24 hours post drug administration.

\section{Behavioral Testing}

\section{Light Dark Box Test}

Light dark transition test is renowned for analyzing anxiety in rodents. The test is centered on rodent's inborn aversive behavior to bright places and exploration in response to drugs or stresses [30]. Light/Dark box consists of two chambers of equal size made up of transparent and black opaque Plexiglas (20 $\times 30 \times 30 \mathrm{~cm}$ ). The partition is dividing the compartment has a $10 \times 10 \mathrm{~cm}$ door in the middle of wall through which rat can move from one chamber to another. Single animal was positioned in the mid of bright chamber fronting towards opposite side from the middle wall opening. Behaviors measured were entries and time spent in light box for 05 minutes.

\section{Elevated Plus Maze}

Elevated plus maze (EPM) has been commonly endorsed to perceive anxiety in rats [31]. The maze consists of plus shaped four arms in which two arms are open $(50 \times 10 \mathrm{~cm})$ and two closed arms $(50 \times 20$ $\mathrm{cm}$ ) with $15 \mathrm{~cm}$ elevated opaque walls. Open arms edges were $25 \mathrm{~cm}$ high to avoid fall of rat. The maze was $100 \mathrm{~cm}$ higher above the floor. Each rat was positioned at the middle of plus shaped maze facing closed arm. Time spent and numbers of entries in open arms were observed in 5 minutes test period.

\section{Open Field Activity}

Open Field has been used most commonly as an assessment of behavior in animal [32]. Open Field test is an uncomplicated and simple assessment of behaviors that does not require training to animals. The aversive behavior of rodents to bright, open and unfamiliar environment incorporates in various experimental testing in open field test [33]. The apparatus consisted of $76 \times 76 \mathrm{~cm}$ square area with 42 $\mathrm{cm}$ high opaque plastic walls. The base was open field is divided into 25 equal quadrangles. Rat was located in the middle box of arena and exploration, anxiety and ambulation was observed in 5 minutes examination.

\section{Morris Water Test}

Water Maze was designed to observe spatial memory and learning. Primarily two axes bisect each other perpendicularly creating an imagined ' + ' sign that are labeled as North, East, South and West with N, E, $S$ and $W$ symbols respectively. The apparatus used was stainless steel circular tank with the measurement of $37 \mathrm{~cm}$ height, $45 \mathrm{~cm}$ diameter and $12 \mathrm{~cm}$ depth. The goal or platform was stainless steel cylindrical with diameter of $10 \mathrm{~cm}$ and immersed $2 \mathrm{~cm}$ below the surface. Water inside the tank was maintained with the temperature of $23 \pm 2^{\circ} \mathrm{C}$ and powdered milk was added in order to hide the goal for flawless rats tracking of the platform. The test was consisted of two phase i.e. test 


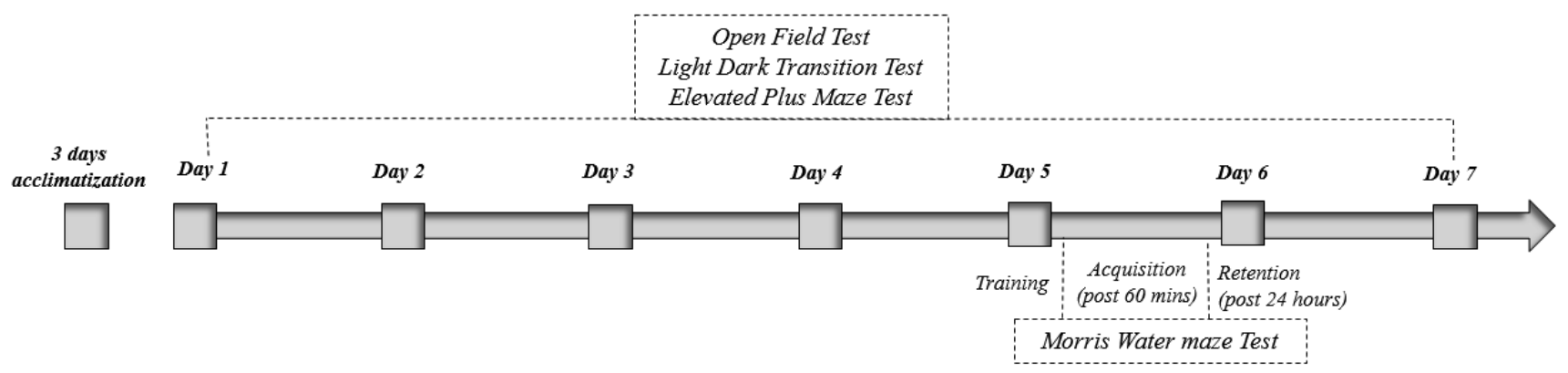

phase and training phase. Animal was given $120 \mathrm{sec}$ in both phases to discover the platform whereas; Experiments were designed to assess long term and short term memory.

\section{Statistical Analysis}

All obtained data were considered as two ways ANOVA repeated measure designs SPSS version 20, followed by tukey's post hoc tests. The results are described as mean \pm SEM. Significance was considered as $p$ value $<0.05$.

\section{RESULTS}

\section{Effects of Sodium Azide (NaN3) Induced Oxidative Stress on Anxiety Assessed by Light/Dark Transition Test}

Figure 1a explains the sodium azide induced oxidative stress anxiogenic effects by numbers of entries in light compartment of light dark transition box. All results were analyzed by two ways ANOVA. Statistical analysis determined the significant effects of days $(F(2,22)=36.680, p<0.05)$, drug treatment $(F(1$, $22)=299.839, p<0.05)$, and days $x$ drug treatment $(F$ $(2, \quad 22)=15.541, \quad p<0.10)$. Post-hoc analysis determined that sodium azide after $1^{\text {st }}, 7^{\text {th }}$ and $14^{\text {th }}$ $(p<0.01)$ administration decreased entries in light compartment significantly when compared to water controls on the same day. Whereas, when both controls and sodium azide (tests) were compared to their first administration, entries in light box decreased significantly after $7^{\text {th }}(p<0.01)$ in controls and after $7^{\text {th }}$, $14^{\text {th }}(p<0.01)$ in sodium azide treated tests animals.

Figure $\mathbf{1 b}$ reveals the anxiogenic effects of sodium azide induced oxidative stress by time spent in light box of light dark test. The results were analyzed by two way ANOVA that demonstrated the effects of days ( $F$ $(2,22)=193.229, p<0.01)$, drug treatment $(F(1,22)=$ 972.234, $\mathrm{p}<0.05)$, and days $\mathrm{x}$ drug treatment interactions $(F(2,22)=120.018, p<0.1)$ were significant. Post-hoc analysis by Tukey's test explained that on the same day sodium azide decreased entries in light compartment significantly after $1^{\text {st }}, 7^{\text {th }}$ and $14^{\text {th }}$ $(p<0.01)$ administration when compared to water controls. Entries in light box decreased significantly after $14^{\text {th }}(p<0.05)$ in controls and after $7^{\text {th }}, 14^{\text {th }}$ $(p<0.01)$ in sodium azide treated tests animals when both controls and sodium azide were compared to their first administration.

\section{Effects of Sodium Azide (NaN3) Induced Oxidative Stress on Anxiety and Stress Assessed by Elevated Plus Maze}

The results of sodium azide induced oxidative stress on number entries in open arms of elevated plus maze are explained in Figure 2a. All results were analyzed by two way ANOVA that demonstrated the effects of days $(F(2,22)=10.262, p<0.10)$, drug treatment $(F(1,22)=131.343, p<0.10)$, and days $x$ drug treatment $(F(2,22)=4.946, p<0.25)$ were significant. Post hoc analysis by tukey's test explained that on the same day sodium azide decreased entries in open arms of elevated plus maze significantly after $1^{\text {st }}, 7^{\text {th }}$ and $14^{\text {th }}(p<0.01)$ administration when compared from water controls. Whereas, decreased numbers of entries in open arms significantly after $7^{\text {th }}, 14^{\text {th }}(p<0.01)$ in water administrated controls as compared to their first administration.

Figure $\mathbf{2 b}$ explains the effects of sodium azide induced oxidative stress on open arms time spent of elevated plus maze. The data were analyzed by two way ANOVA repeated measures design that explained the effects of days $(F(2,22)=11.688, p<0.10)$, drug treatment $(F(1,22)=745.005, p<0.05)$, and days $x$ drug treatment $(F(2,22)=68.456, p<0.05)$ were significant. Post-hoc analysis determined that on the same day sodium azide significantly decreased time spent in open arms of elevated plus maze after 1st, 7 th and 14th $(p<0.01)$ administration when compared from water controls. Whereas, open arms time spent increased significantly after 7 th and 14th $(p<0.01)$ 

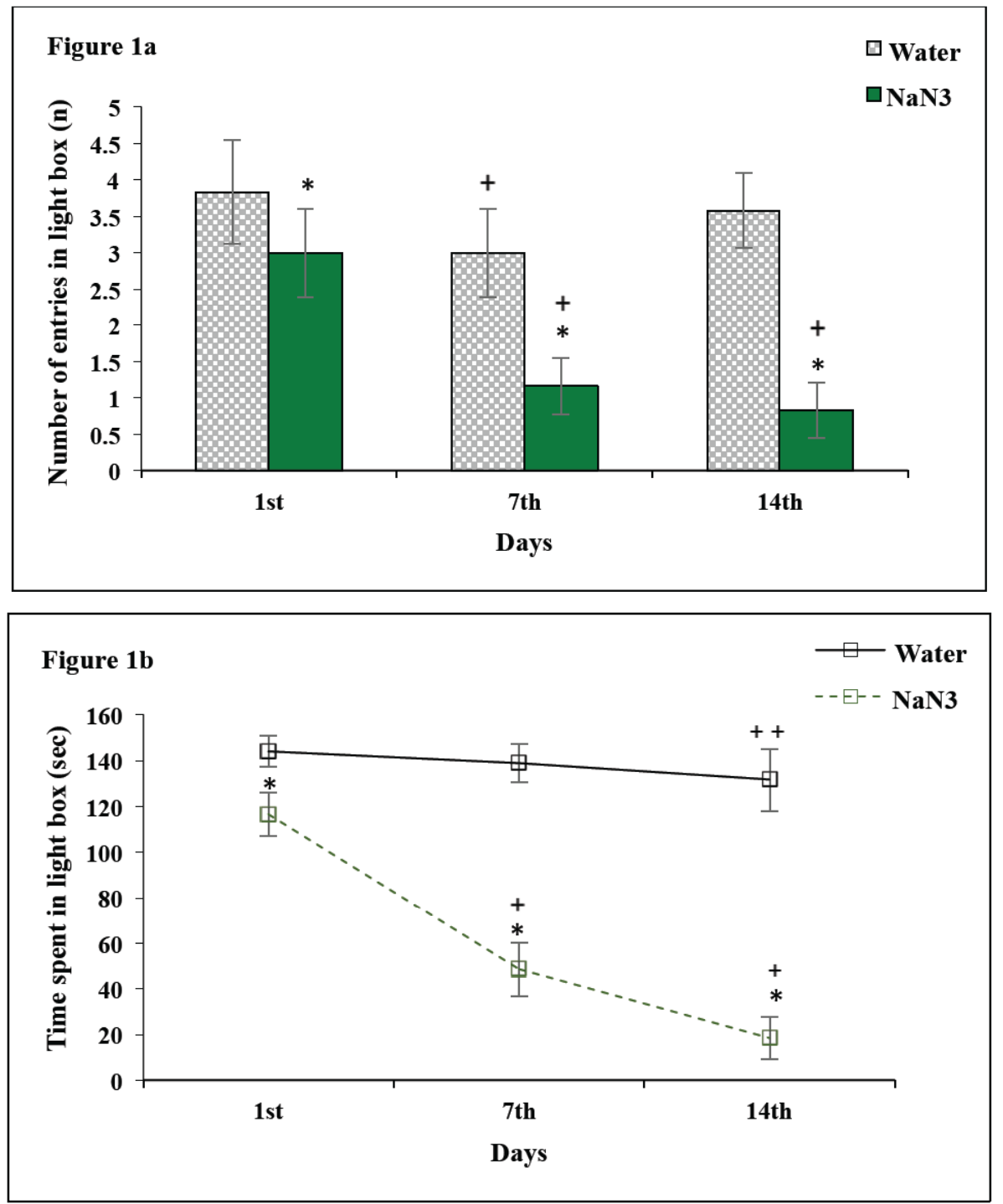

Figure 1: Effects of Sodium Azide (NaN3) induced oxidative stress on anxiety assessed by Light/Dark transition test.

Values are means $\pm S D(n=12)$ as administered post 24 hours of NaN3 treatment. Significant differences by Newman-Keul's test: groups that differ significantly from respective water controls ${ }^{*} \mathrm{p}<0.01 ;+p<0.01$ from similar drug administered groups that significantly differ from $1^{\text {st }}$ administration following two way ANOVA (repeated measure design).

water administration in controls and decreased after 7 th and 14 th $(p<0.01)$ administration of sodium azide as compared to their first administration respectively.

\section{Effects of Sodium Azide (NaN3) Induced Oxidative Stress on Locomotion and Anxiety Assessed in Open Field}

The effects of oxidative stress on latency to move in open field box are explained by Figure 3a. All results were determined by two way ANOVA that explained the significant effects of days $(F(2,22)=22.461$, $p<0.05)$, drug treatment $(F(1,22)=390.928, p<0.05)$, and days $x$ drug treatment $(F(2,22)=52.106, p<0.05)$. Tukey's test Post-hoc analysis explained that on the same day sodium azide increased latency to move in open field arena significantly after $7^{\text {th }}$ and $14^{\text {th }}(p<0.01)$ administration when compared from water controls. Whereas, latency decreased significantly after $14^{\text {th }}$ $(p<0.01)$ in water controls and increased after $7^{\text {th }}$ and $14^{\text {th }}(p<0.01)$ administration of sodium azide when compared with their first administration.

Figure $\mathbf{3 b}$ explains the effects of sodium azide induced oxidative stress by numbers of square crossed. The results were analyzed by two way ANOVA which described the effects of days $(F(2,22)$ $=43.938, p<0.05)$, drug treatment $(F(1,22)=$ 1415.118, $p<0.05)$, and days $x$ drug treatment interaction $(F(2,22)=37.853, p<0.05)$ were significant. Post hoc analysis determined that sodium azide after $1^{\text {st }}, 7^{\text {th }}$ and $14^{\text {th }}(p<0.01)$ administration significantly decreased number of square crossed on the same day 

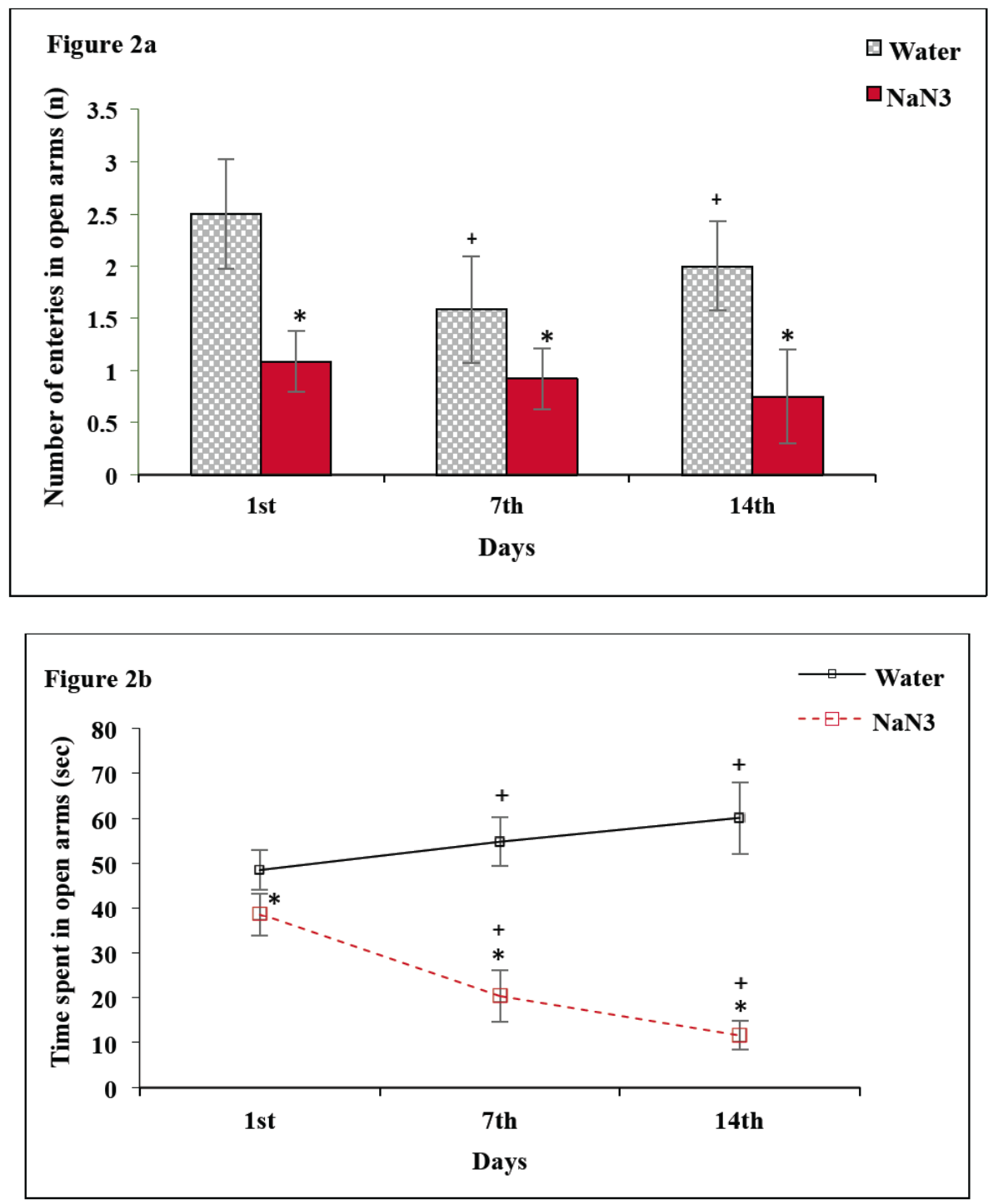

Figure 2: Effects of Sodium Azide (NaN3) induced oxidative stress on Anxiety and stress assessed by Elevated Plus Maze.

Values are means \pm SD $(n=12)$ as administered post 24 hours of NaN3 treatment. Significant differences by Newman-Keul's test: groups that differ significantly from respective water controls ${ }^{*} p<0.01 ;+p<0.01$ from similar drug administered groups that significantly differ from $1^{\text {st }}$ administration following two way ANOVA (repeated measure design).

comparison with water controls. Whereas, number of square crossed decreased after $7^{\text {th }}(p<0.01)$ in controls and after $7^{\text {th }}, 14^{\text {th }}(p<0.01)$ in sodium azide treated tests animals significantly when both controls and sodium azide (tests) were compared to their first administration.

\section{Effects of Sodium Azide (NaN3) Induced Oxidative Stress on Memory and Learning Assessed by Morris Water Maze}

Figure 4 determines the effects of sodium azide induced oxidative stress on memory and learning in Morris water maze. All data were analyzed by two way ANOVA that demonstrated the effects of sessions ( $F$ $(2,22)=314.765, p<0.01)$, drug treatment $(F(1,22)=$
$599.560, p<0.05)$, and interaction between sessions and drug treatment $(F(2,22)=110.351, p<0.01)$ were significant. Post-hoc analysis by Tukey's test explained that acquisition $(p<0.01)$ and retention $(p<0.01)$ decreased significantly after sodium azide administration when compared from water controls. Whereas, significantly increased acquisition $(p<0.01)$ and retention $(p<0.01)$ in water controls and sodium azide test animals when compared with their first administration respectively.

\section{DISCUSSION}

Present study was designed to describe the effects of behaviors caused by brain oxidative stress which was induced by sodium azide at the selected dose of 5 

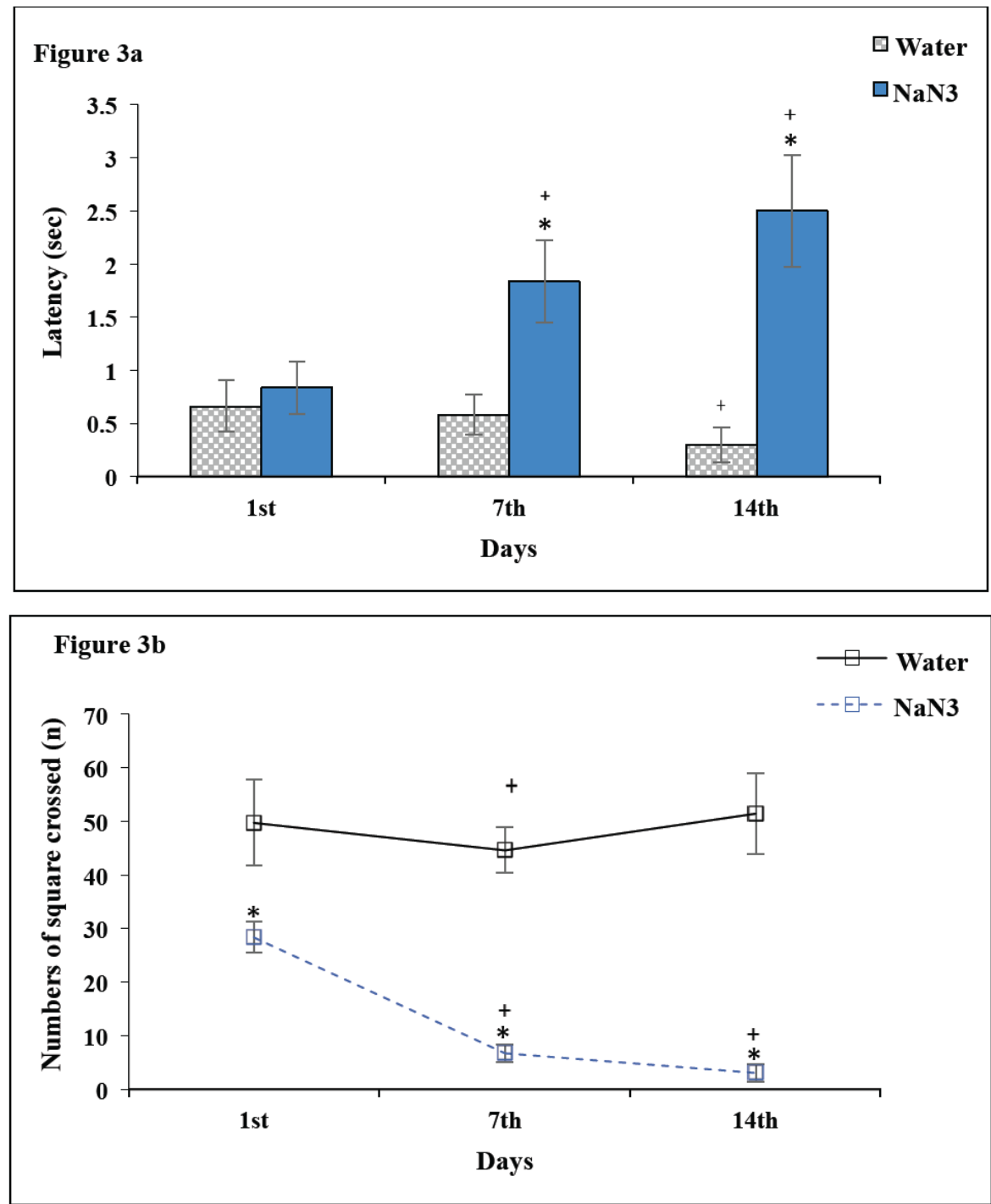

Figure 3: Effects of Sodium Azide (NaN3) induced oxidative stress on anxiety and locomotion assessed by Open Field test.

Values are means \pm SD $(n=12)$ as administered post 24 hours of NaN3 treatment. Significant differences by Newman-Keul's test: groups that differ significantly from respective water controls ${ }^{*} p<0.01 ;+p<0.01$ from similar drug administered groups that significantly differ from $1^{\text {st }}$ administration following two way ANOVA (repeated measure design).

$\mathrm{mg} / \mathrm{kg}$ per body weight for two weeks. Currently, oxidative stress definition is derived from the basic concept of 'antioxidants and oxidants imbalance' [34] to 'pro-oxidants and antioxidants imbalance that is associated with redox circuitry and destructions of macromolecules [35]. Sodium azide has been extensively used in laboratory, medicine, insecticides, herbicides and antibacterial agents. Recent studies determine the NaN3 poisoning caused hypotensive effects that are due to its vasodilator effects [36, 37]. Sodium azide is known to cause excitotoxicity and degeneration by increasing the mitochondrial membrane permeability via lipid peroxidation [38] that leads to mitochondrial $\mathrm{Ca}^{+2}$ and $\mathrm{H}_{2} \mathrm{O}_{2}$ production increasing the $\mathrm{Ca}^{+2}$ levels i.e. ROS dependent calcium production [39].
Figure $1 \mathrm{a}$ and $\mathbf{1 b}$ determined the oxidative stress induced anxiety and stress in light dark test. Light/dark box is used for evaluating rodent's natural aversive behavior to bright area preferring darker one. Studies determined this aversive behavior as rats that were treated with anxiogenic treatments did not explore light box but prefer to enter inside dark compartment and remain immobile and tend to freeze for test sessions [40]. Two parameters were selected including entries in light compartment and time spent while exploring illuminated transparent box of light dark transition paradigm. significant decrease in entries were observed in sodium azide administered test animals in 14 days with lesser time spent in light box indicating anxiety and stress due to oxidative stress caused by sodium azide treatment whereas, controls were less 


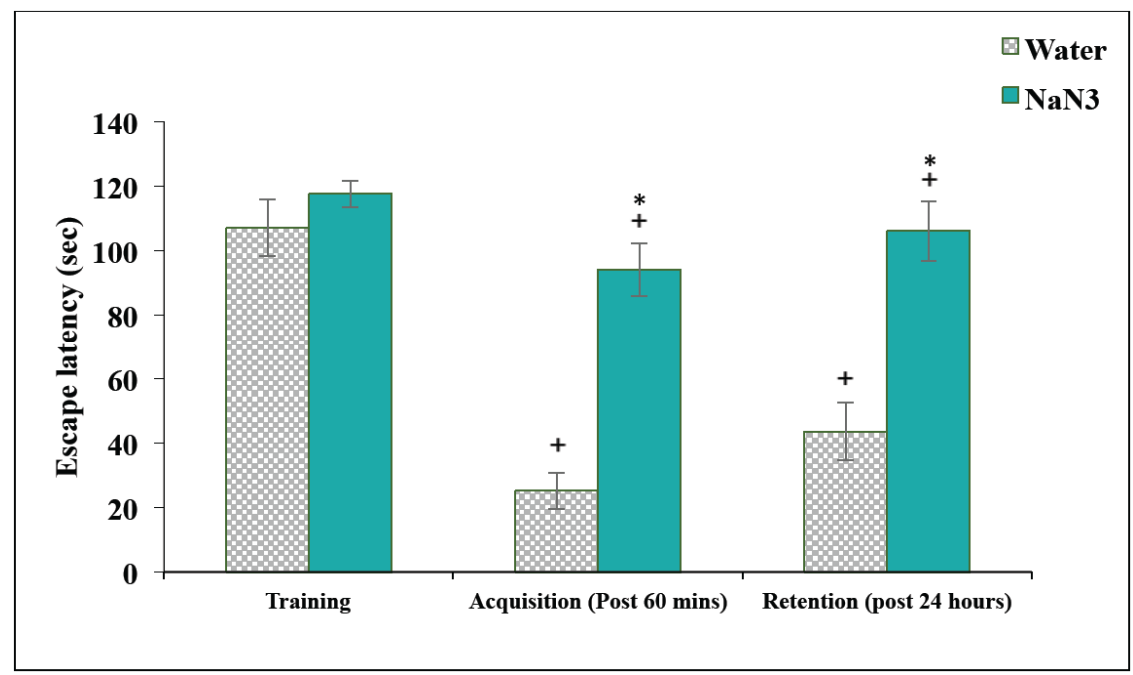

Figure 4: Effects of Sodium Azide (NaN3) induced oxidative stress on memory and learning assessed by Morris water Maze.

Values are means \pm SD $(n=12)$ as administered post 24 hours of NaN3 treatment. Significant differences by Newman-Keul's test: groups that differ significantly from respective water controls ${ }^{*} p<0.01 ;+p<0.01$ from similar drug treated groups that significantly differ from training session following two way ANOVA (repeated measure design).

stressed and increased numbers of entries and time spent is observed in water control after $7^{\text {th }}$ and $14^{\text {th }}$ observations exploring light compartment due to nonoxidative brain conditions.

Elevated plus maze in Figure $\mathbf{2 a}$ and $\mathbf{2 b}$ explains the anxiogenic and stressed behavior in test animals that were treated with sodium azide regularly for two weeks. Elevated plus maze test with two unopened arms were designed to determine avoidance and fear in rodents [41, 42]. Anxiety like symptoms induced substances that cause reduced open arms entries with increased time spent in closed arms [31]. Decreased numbers of entries and time spent in open arms were observed in test animals that reveal the brain oxidative state causing anxiety and stress that inhibits the animal from entering and discovering open lit area. While, controls animals spent more time in open arms with higher number of entries due to non-oxidative state of brain.

Figure $\mathbf{3 a}$ and $\mathbf{3 b}$ described the oxidative stress induced locomotive and exploring effects assessed in open field arena in test animals treated with sodium azide daily. Hall in 1934 introduced open field as a measuring tool for rats emotions considering that a rat having high emotions did not explore and move around frequently compared to rat having less emotions [43]. All animals that were administered with sodium azide increased latency after $7^{\text {th }}$ and $14^{\text {th }}$ administration significantly with less numbers of square crossed whereas, controls exhibited decreased latency and more box crossed after weekly observations. This behavior indicates the oxidative stress induced behavioral deficits in test animals.

Figure 4 reveals the impairment in memory and learning in animals that were treated with sodium azide in Morris water maze. In 1984, Morris described procedures and specifics for monitoring various forms of memory and cognition [44]. Animals produced decreased leaning acquisition after 60 mins with deficit memory retention after 24 hours session indicating diminishing memory and learning capabilities in test animals whereas, control that were administered with water only revel increased learning and memory retention.

\section{CONCLUSION}

In conclusion, our study demonstrated that repetitive sodium azide treatment can induce oxidative stress that leads to behavioral deficits and psychopathologies. Further investigations should be carried out for sodium azide damages in brain regions and its treatment.

\section{REFERENCES}

[1] Orgel, L.E. The maintenance of the accuracy of protein synthesis and its relevance to ageing. Proceedings of the National Academy of Sciences of the United States of America 1963; 49(4): 517-521. https://doi.org/10.1073/pnas.49.4.517

[2] Harman, D. Aging: A theory based on free radical and radiation chemistry. Journal of Gerontology 1956; 11(3): 298-300.

https://doi.org/10.1093/geronj/11.3.298 
[3] Racker, E. Mechanisms of energy transformations. Annual Review of Biochemistry 1977; 46: 1006-1014. https://doi.org/10.1146/annurev.bi.46.070177.005042

[4] Schafer, F.Q.Buettner, G.R. Redox environment of the cell as viewed through the redox state of the glutathione disulfide/glutathione couple. Free Radical Biology and Medicine 2001; 30(11): 1191-1212.

https://doi.org/10.1016/S0891-5849(01)00480-4

[5] Aung-Htut, M.T., Ayer, A., Breitenbach, M., Dawes, I.W. Oxidative stresses and ageing. Subcellullar Biochemistry 2012; 57: 13-54.

https://doi.org/10.1007/978-94-007-2561-4_2

[6] Lushchak, V.I. Free radicals, reactive oxygen species, oxidative stress and its classification. Chemical-Biological Interactions 2014; 224C, 164-175. https://doi.org/10.1016/j.cbi.2014.10.016

[7] Irie, M. Asami, S. Ikeda, M. Kasai, H. Depressive state relates to female oxidative DNA damage via neutrophil activation. Biochemical and Biophysical Research Communications 2003; 311(4): 1014-1018. https://doi.org/10.1016/j.bbrc.2003.10.105

[8] Epel, E.S. Blackburn, E.H. Lin, J. Dhabhar, F.S. Adler, N.E. Morrow, J.D. Cawthon, R.M. Accelerated telomere shortening in response to life stress. Proceedings of the National Academy of Sciences of the United States of America 2004; 101(49): 17312-17315.

https://doi.org/10.1073/pnas.0407162101

[9] Forlenza, M.J. Miller, G.E. (2006). Increased serum levels of 8-hydroxy2'-deoxyguanosine in clinical depression. Psychosomatic Medicine 2006; 68(1): 1-7.

https://doi.org/10.1097/01.psy.0000195780.37277.2a

[10] Gidron, Y. Russ, K. Tissarchondou, H. Warner, J. The relation between psychological factors and DNA-damage: a critical review. Biological Psychology 2006; 72(3): 291-304. https://doi.org/10.1016/j.biopsycho.2005.11.011

[11] Davies, K.J. Oxidative stress: the paradox of aerobic life. Biochemical Society Symposia 1995; 61: 1-31. https://doi.org/10.1042/bss0610001

[12] Berg, D., Youdim, M.B., Riederer, P. Redox imbalance. Cell and Tissue Research 2004; 318(1): 201-213. https://doi.org/10.1007/s00441-004-0976-5

[13] Kohen, R. Nyska, A. Oxidation of biological systems: oxidative stress phenomena, antioxidants, redox reactions, and methods for their quantification. Toxicologic Pathology 2002; 30(6): 620-650. https://doi.org/10.1080/01926230290166724

[14] Konat, G.W. H2O2-induced higher order chromatin degradation: a novel mechanism of oxidative genotoxicity. Journal of Biosciences 2003; 28(1): 57-60. https://doi.org/10.1007/BF02970132

[15] Raha, S., Robinson, B.H. Mitochondria, oxygen free radicals, and apoptosis. American Journal of Medicinal Genetics 2001; 106(1): 62-70.

https://doi.org/10.1002/ajmg.1398

[16] Aksenova, M.V. Aksenov, M.Y. Mactutus, C.F. Booze, R.M. Cell culture models of oxidative stress and injury in the central nervous system. Current Neurovascular Research 2005; 2(1): 73-89.

https://doi.org/10.2174/1567202052773463

[17] Berk, M. Ng, F. Dean, O., Dodd, S. Bush, A.I. Glutathione: a novel treatment target in psychiatry. Trends in Pharmacological Sciences 2008; 29(7): 346-351. https://doi.org/10.1016/j.tips.2008.05.001

[18] Filomeni, G. Ciriolo, M.R. Redox control of apoptosis: an update. Antioxidants \& Redox Signaling 2006; 8(11-12): 2187-2192. https://doi.org/10.1089/ars.2006.8.2187

[19] Rippen HE, Lamm SH, Nicoll PG, Cummings L, Howearth G, Thayer D. Occupational health data as a basis for process engineering changes: development of safe work environment in the sodium azide industry. International Archives of Occupational and Environmental Health 1996; 68(6): 459-68. https://doi.org/10.1007/BF00377870

[20] Health \& Safety Executive. Consultation Document European Commission Directive under the Chemical Agents Directive 98/24/ EC to establish a First Consolidated List of Indicative Occupational Exposure Limit Values at European Community level 2002.

[21] Lee EW. Sodium azide: bioavailability and metabolism in rats. Toxicologist 1982; 2: 24.

[22] Eyer P. Stickstoffwasserstoffsäure, Azide (Hydrazoic acid, azides). In: Marquard H, Schäfer SG (Eds) Lehrbuch der Toxikologie (Textbook of Toxicology) (German), B I Wissenschaftsverlag, Mannheim 1994; 565-66.

[23] Smith RP, Louis CA, Kruszyna R, Kruszyna H. Acute neurotoxicity of sodium azide and nitric oxide. Fundamental and Applied Toxicology 1991; 17(1): 120-127.

https://doi.org/10.1016/0272-0590(91)90244-X

[24] Su B, Wang X, Lee H-G, Tabaton M, Perry G, Smith MA, Zhu $X$. Chronic oxidative stress causes increased tau phosphorylation in M17 neuroblastoma cells. Neuroscience Letters 2010; 468(3): 267-271.

https://doi.org/10.1016/j.neulet.2009.11.010

[25] Chang J, Yang JY, Choi J, Jung HH, Im GJ. Calcium imaging in gentamicin ototoxicity: Increased intracellular calcium related to oxidative stress and late apoptosis. International Journal of Pediatric Otorhinolaryngology 2011; 75(12): 16161622.

https://doi.org/10.1016/j.ijporl.2011.09.027

[26] Liu B, Che W, Zheng C, Liu W, Wen J, Fu H, Tang K, Zhang J, Xu Y. SIR T5: A safeguard against oxidative stressinduced apoptosis in cardiomyocytes. Cell Physiology and Biochemistry 2013; 32(4): 1050-1059.

https://doi.org/10.1159/000354505

[27] Luques L, Shoham S, Weinstock M. Chronic brain cytochrome oxidase inhibition selectively alters hippocampal cholinergic innervation and impairs memory: Prevention by ladostigil. Experimental Neurology 2007; 206(2): 209-219. https://doi.org/10.1016/j.expneurol.2007.04.007

[28] Marino S, Marani L, Nazzaro C, Beani L, Siniscalchi A. Mechanisms of sodium azideinduced changes in intracellular calcium concentration in rat primary cortical neurons. Neurotoxicology 2007; 28(3): 622-629.

https://doi.org/10.1016/j.neuro.2007.01.005

[29] Ahmed Mae, Farouk Fahmy H. Histological study on the effect of sodium azide on the corpus striatum of albino rats and the possible protective role of Lcarnitine. The Egyptian Journal of Histology 2013; 36(1): 39-49. https://doi.org/10.1097/01.EHX.0000424089.76006.d7

[30] Crawley JN, Goodwin FK. Preliminary report of a simple animal behavior model for the anxiolytic effects of benzodiazepines. Pharmacol Biochem Behav 1980; 13(2): 167-170. https://doi.org/10.1016/0091-3057(80)90067-2

[31] Pellow S, Chopin P, File SE, Briley M. Validation of open: closed arm entries in an elevated plus-maze as a measure of anxiety in the rat. Journal of Neuroscience Methods 1985; 14(3): $149-67$. https://doi.org/10.1016/0165-0270(85)90031-7

[32] Walsh, R. N., Cummins, R. A. The open field test: a critical review. Psychological Bulletin 1976; 83: 482-504.

[33] Choleris, E., Thomas, A. W., Kavaliers, M., Prato, F. S. A detailed ethological analysis of the mouse open field test: effects of diazepam, chlordiazpoxide and an extremely low frequency pulsed magnetic field. Neuroscience \& Biobehavioral Reviews 2001; 25(3): 235-260. https://doi.org/10.1016/S0149-7634(01)00011-2

[34] Sies, H. Oxidative stress: introductory remarks. Oxidative Stress, Academic Press London 1985; 1-8. https://doi.org/10.1016/B978-0-12-642760-8.50005-3 
[35] Jones, D.P. Redefining oxidative stress. Antioxidants \& Redox Signaling 2006; 8(9-10), 1865-1879. https://doi.org/10.1089/ars.2006.8.1865

[36] A.N. Swafford, I.N. Bratz, J.D. Knudson, P.A. Rogers, J.M. Timmerman, J.D. Tune. C-reactive protein does not relax vascular smooth muscle: effects mediated by sodium azide in commercially available preparations, American Journal of Physiology. Heart Circulatory Physiology 2005; 288(4): H1786-H1795.

https://doi.org/10.1152/ajpheart.00996.2004

[37] E. Qamirani, H.H. Razavi, X. Wu, M.J. Davis, L. Kuo, T.W. Hein. Sodium azide dilates coronary arterioles via activation of inward rectifier $\mathrm{K}+$ channels and $\mathrm{Na}+-\mathrm{K}+-\mathrm{ATPase}$. American Journal of Physiology-Heart and Circulatory Physiology 2006; 290(4): H1617-H1623. https://doi.org/10.1152/ajpheart.00746.2005

[38] V.S. Van Laar, N. Roy, A. Liu, S. Rajprohat, B. Arnold, A.A. Dukes, C.D. Holbein, S. B. Berman. Glutamate excitotoxicity in neurons triggers mitochondrial and endoplasmic reticulum accumulation of Parkin, and, in the presence of $\mathrm{N}$-acetyl cysteine, mitophagy. Neurobiology of Diseases 2014; 74: 180-193.

https://doi.org/10.1016/j.nbd.2014.11.015

[39] D.J. Dukoff, D.W. Hogg, P.J. Hawrysh, L.T. Buck. Scavenging ROS dramatically increase NMDA receptor whole-cell currents in painted turtle cortical neurons. Journal of Experimental Biology 2014; 217 (Pt 18) 3346-3355. https://doi.org/10.1242/jeb.105825

[40] Ardayfio, P., \& Kim, K. S. Enhanced freezing in the lightdark box after anxiogenic treatments. Unpublished observations 2004 .

[41] Montgomery, K. C. "Spontaneous alternation" as a function of time between trials and amount of work. Journal of Experimental Psychology 1951; 42(2): 82-93. http://dx.doi.org/10.1037/h0059834

[42] Montgomery, K. C. The relation between fear induced by novel stimulation and exploratory drive. Journal of Comparative and Physiological Psychology 1955; 48(4): 254260. http://dx.doi.org/10.1037/h0043788

[43] Hall, C. S. Emotional behavior in the rat. I. Defecation and urination as measures of individual differences in emotionality. Journal of Comparative Psychology 1934; 18(3): 385-403.

http://dx.doi.org/10.1037/h0071444

[44] Stewart, CA. Morris, RGM. The watermaze. In: Sahgal, A., editor. Behavioural Neuroscience, Volume I, A Practical Approach. IRL Press at Oxford University Press; Oxford. 1993; 107-122. 